\title{
Incursões funcionalistas em análise: teoria e prática
}

\author{
Maria Helena de Moura NEVES (1) \\ Universidade Presbiteriana Mackenzie (UPM) \\ Universidade Estadual Júlio de Mesquita Filho (UNESP/Araraquara)
}

\section{○}

OPEN ACCESS

COMO CITAR

Neves, M. H. M.; Mackenzie, J. L.; Coneglian, A. V. L. (2020). Incursões funcionalistas em análise: teoria e prática. Revista da Abralin, v. 19, n. 3, p. 17-24, 2020.
John Lachlan MACKENZIE (1)

Vrije Universiteit Amsterdam (VUA)

André Vinícius Lopes CONEGLIAN (1)

Universidade Federal de Minas Gerais (UFMG)

\section{Apresentação: A proposta de um dossiê de estudos de orientação funcionalista}

Na direção de fortalecer vínculos de pesquisa entre as universidades brasileiras e as universidades estrangeiras, a Abralin (Associação Brasileira de Linguística) promoveu a produção de 4 dossiês temáticos especiais de Linguística, com pesquisadores do Brasil e do exterior, para publicação na Revista da Abralin, estabelecendo a inclusão de textos não apenas em língua portuguesa mas também em língua inglesa.

Historicamente, tem de ser observado o fato significativo de que essa iniciativa da Abralin veio imediatamente na sequência da promoção, por essa associação, do "Abralin ao Vivo", uma série de eventos (conferências e mesas-redondas), que se desenvolveram on-line a partir de maio de 2020, e que se estão prolongando para 2021. Na ocasião a Associação Brasileira de Linguística justificava essa promoção refletindo sobre o momento que se vivia, marcado pelo distanciamento social a que a pandemia obrigava, e paralelamente se dirigia a seus associados registrando a necessidade de que se preservasse "o avanço da ciência e o intercâmbio de ideias entre pesquisadores" "para continuar subsidiando ações técnicas e decisões políticas fundamentadas no conhecimento científico". Foi assim que passaram a ocorrer atividades de divulgação de pesquisas que envolveram - e estão envolvendo, e estão congregando - um grande número de pesquisadores do Brasil e do exterior, incluídos 


\section{REVISTA DA ABRALIN}

nomes extremamente representativos dentro da ciência linguística, e, relevantemente, dentro da pesquisa de orientação funcionalista.

Essa iniciativa da Abralin tem de ser destacada como de grande importância no macrocosmo da linguística, como um marco da internacionalização das pesquisas linguísticas, e particularmente quanto à divulgação do contexto de pesquisa brasileiro. Merece ser referido o fato de que colegas não brasileiros têm afirmado que poucos pesquisadores de outros países conheciam a Abralin antes do ano de 2020, mas que a "Abralin ao Vivo" causou uma impressão profunda e muito positiva em todos os que participaram desses recentes eventos, como conferencistas, palestrantes, moderadores ou ouvintes. E é importante registrar que, dentre os autores que estão neste dossiê, quatro participaram do evento, ou como conferencistas ou como integrantes de mesas temáticas, tendo sido impossível mais colaborações com tal tipo de autoria, nesta publicação, pela premência do tempo para entrega dos originais. Também foram conferencistas no evento dois dos organizadores deste dossiê, Maria Helena de Moura Neves e Lachlan Mackenzie, mas os três organizadores consideraram apropriado não concorrer à publicação de artigo nesta obra.

\section{A natureza e a configuração geral da obra}

Dentro desse Programa de publicação lançado pela Abralin, nós, os organizadores desta obra, submetemos à Presidência da Associação a proposta do dossiê, estabelecendo como foco temático o Funcionalismo linguístico, ou Linguística funcional, ou Gramática funcional. A proposta visou à produção de uma obra que pudesse constituir um mapeamento de temas de seleção atual, dentro do universo das diversas proposições teóricas de orientação funcionalista. A direção geral da obra privilegiou, pois, contemplar-se uma discussão de temas teoricamente dirigida, e não a explicitação, em si e por si, de determinadas propostas teóricas funcionalistas.

O resumo enviado à Abralin estabelecia os seguintes pontos para a condução deste número do periódico Revista da Abralin:

1) No Funcionalismo linguístico, concebe-se a linguagem como um fenômeno evolutivoadaptativo pelo qual a gramática das línguas naturais se organiza com base em descrições da estrutura linguística.

2) Acredita-se que, nesse enquadre, é possível chegar a explicações para o modo pelo qual a gramática das línguas naturais opera descrições da estrutura linguística, considerada a interface entre os componentes sintático, semântico e pragmático.

3) Inúmeras propostas funcionalistas orientam eficientemente esse tipo de descrição, privilegiando a organização semântico-pragmática da gramática para explicitação dos 


\section{REVISTA DA ABRALIN}

processos gramaticais constitutivos dos enunciados, seja com vista ao componente sócio-cognitivo, seja com vista aos aspectos tipológicos e universais.

O texto de proposta do dossiê prosseguia na indicação de que, dentro de tal moldura, o dossiê se propunha reunir estudos representativos do desenvolvimento contemporâneo das diversas correntes ditas "funcionalistas", entendendo-se como inscrita nesse amplo contexto de direção investigativa a descrição de aspectos gramaticais das línguas naturais, sendo especialmente bem-vindos estudos que discutam, na teoria e na prática, temas como: enquadre sócio-cognitivo dos usos linguísticos; relação entre discurso e gramática; iconicidade, economia e competição de motivações; variação e mudança na gramática das línguas naturais; mapeamento categorial na cognição e na linguagem; fluidez de categorias; prototipia e exemplaridade; processos gramaticais constitutivos do enunciado; relação entre construções gramaticais; tipologia linguística; universais linguísticos.

Afinal, indicou-se que temas correlatos, tratados na direção funcionalista, tanto de um ponto de vista teórico quanto de um ponto de vista aplicado, também teriam abrigo na publicação.

Quanto ao perfil dos autores desejados, entendeu-se que não necessariamente se priorizassem acadêmicos com experiência, mas que jovens pesquisadores seriam bem-vindos, privilegiando-se decisivamente a representatividade do material a ser publicado.

\section{Uma meta-análise da série de incursões funcionalistas que compõem o dossiê}

A obra se abre com o artigo de Adriana Pagano Modelagem da linguagem e do contexto na teoria sistêmico-funcional, que oferece um bem cuidado mapeamento da arquitetura sistêmico-funcional hallidayiana, incorporadas no tratamento as atualizações pelas quais a teoria passou. Nesse mapeamento se delineiam, para o geral das questões, as dimensões em que se resolve a organização da linguagem que essa arquitetura propõe: as "dimensões globais" (estratificação, instanciação e metafunção) e as "dimensões locais" (estrutura e sistema). A linha de condução do artigo também acomoda as duas concepções centrais de Halliday: a de que a linguagem é 'naturalmente' complexa; e a de que a linguagem se resolve teoricamente pelas "escolhas", implicando "seleções". Marca-se, pois, a relevância de uma visão paradigmática de opções disponíveis, dentro daquilo que as diferentes dimensões de organização da linguagem englobam. O corolário é que o significado é gerado pelo contraste sistêmico, aquele que se dá entre cada forma escolhida e todas as outras formas que deixaram de ser selecionadas. E essa noção de 'escolha' é também a que se envolve na proposta sistêmico-funcional das "metafunções", definíveis como coocorrências de seleções sistêmicas voltadas não apenas para a construção de nossa experiência de mundo e de nossas relações sociais, mas 


\section{REVISTA DA ABRALIN}

também para a própria construção do texto, uma função capacitadora e facilitadora da linguagem, afinal.

$\mathrm{O}$ artigo da Natalia Levshina, Efficient trade-offs as explanations in functional linguistics: some problems and an alternative proposal, que vem a seguir, toma dados provenientes de um córpus de 30 línguas (a base de dados Universal Dependencies) e de um córpus anotado (notícias da coleção Leipzig Corpora) para discutir a noção de "troca eficiente" (efficient trade-off), um conceito correntemente invocado, na linguística funcional, para explicar vários aspectos do uso e da estrutura da linguagem. Ao definirem a eficiência segundo a razão entre custo e benefício, os linguistas têm reservado o conceito de "efficient trade-off" às correlações negativas estabelecidas entre duas explicações de direções opostas, cada uma das quais resulta de "escolhas racionais". O estudo se desenvolve no sentido de não reconhecer vantagem em tomar essa noção intuitivamente atraente para direcionamento das análises, considerando-a como "mais confusa do que esclarecedora", até porque nem toda correlação negativa representa uma troca real. São arrolados inúmeros problemas associados ao aproveitamento desse conceito de "troca eficiente" para explanações em linguística funcional, apontando-se as vantagens em substituir aquela análise baseada na correlação negativa entre pares de variáveis linguísticas por uma análise causal que contemple uma multidão de fatores e problematize a ideia consensual de que as línguas tendem a ser eficientes. A conclusão é que seria conveniente desistir completamente do conceito traiçoeiro de "troca eficiente", substituindo o recurso a correlações pela extração de relações causais unidirecionais, exemplificadas no artigo pela conclusão depreendida da análise dos dados de que a ordem das palavras determina a marcação de caso, mas não vice-versa.

O terceiro artigo, A functionalist typology of redundancy, de Sterre Cécile Leufkens dedica-se ao estudo da redundância linguística - a "repetição de informação", como define a autora - fato gramatical que vem destacado como de interesse particular na pesquisa funcionalista. Aponta-se que esse fenômeno, muito comum na linguagem coloquial, tem sido considerado nos estudos como fundamental para a arquitetura da linguagem (e até como um universal linguístico), mas tem recebido pouco estudo empírico, talvez pelo fato de que, sendo os fenômenos redundantes tão "onipresentes" nas línguas, seu estudo se apresenta como tarefa impossível. E é precisamente isso - defende o artigo - que torna a redundância sintagmática um objeto de investigação extremamente relevante na perspectiva funcionalista, pois facilmente essa onipresença é atribuível à sua funcionalidade. Desse modo, o objetivo do estudo propõe-se como uma busca funcional da motivação das diferentes formas da redundância, bem como das funções comunicativas de quatro tipos de concordância destacados, o que se conduz pela análise de gramáticas de referência de uma amostra de 50 idiomas variados. Os resultados encontram duas respostas valiosas: determinados tipos de concordância mostram-se como quase universais enquanto outros se mostram restritos a poucas línguas; a necessidade de precisão e a necessidade de ênfase em informações cruciais são os fatores que motivam a concordância, e cada um deles opera no sentido de uma redundância diferente ("fortuita" e "propositada", respectivamente). A essas conclusões soma-se, ainda, a verificação de que, para cada um desses dois tipos de redundância, pode-se estabelecer um desenvolvimento diacrônico característico. 


\section{REVISTA DA ABRALIN}

O artigo Typology and nuance: relativization, de Marianne Mithun defende a ideia de que os trabalhos de tipologia linguística são extremamente valiosos para explorar não apenas o que as línguas têm em comum mas também o modo como elas diferem uma da outra, e ainda quais as possíveis correlações entre as variáveis existentes. A proposta parte da noção de que a investigação linguística verifica, primariamente, os elementos de compartilhamento entre as línguas, indo à avaliação o modo como elas variam e também à causa da variação, tudo envolvendo a identificação de categorias que possam embasar tal comparação. O ponto de partida da argumentação é que a maior parte do que se oferece na tipologia linguística é inerentemente categórico, ou seja, as classificações se fazem em termos de "presença" ou "ausência" de traços, escolha que permite uma boa condução das análises em determinados casos, entretanto não em muitos outros, que exigem a adoção de uma visão mais atenta ao matizamento da linguagem. Segundo a autora, falta, pois, uma visão que avalie até que ponto uma expressão linguística, ou uma distinção apontada, ou uma variável, tem delimitação categorial determinantemente instaurada na gramática da língua. Quanto à condução do exame, a autora propõe, com toda propriedade, que ele vá à transcrição de fala espontânea, garantindo, assim, uma análise que contemple a funcionalidade do contexto de enunciação, acompanhada de uma análise prosódica. O exame oferecido toma o mohawk, língua iroquesa indígena do nordeste da América do Norte, e o fato em análise, no desenvolvimento da proposta, é a construção das orações "relativas", com a hipótese de que essas construções parecem não estar ainda bem instaladas na gramática. Entretanto, a autora considera que os resultados de sua análise, revelando fatos particulares dessa língua, têm o seu valor dentro da pesquisa tipológica, e, mais que isso, permitem uma generalização de tipo funcional que merece ser destacada. Ao final, pode-se indicar como ponto altamente relevante do estudo a demonstração que ele faz de que o trabalho de tipologia linguística pode enriquecer-se com o reconhecimento de que as "categorias" e as "variáveis" que compõem a teoria nem sempre são rigidamente 'categóricas', nas línguas particulares.

O quinto artigo, Espectro funcional de bem e bom no português falado: instâncias de gramaticalização, de Edair Maria Gorski, descreve funcionalmente os itens bem e bom. Ele parte do fato, já bastante tratado nas investigações, de que essas palavras, categorizadas em sua origem como, respectivamente, advérbio (do latim bene) e adjetivo (do latim bonus, a, um), apresentam usos com a categoria original preservada e usos com a função adquirida de marcadores discursivos, além de outras, ainda. Examinando situações dialógicas em 72 entrevistas sociolinguísticas do Projeto VARSUL, a autora trata comparativamente os usos discursivos dos itens em exame, com o propósito de depreender padrões de comportamento, considerando-os como instâncias de "gramaticalização" (mais estritamente, de "expansão"), provendo a interpretação das mudanças encontradas e pondo em relevo o papel do contexto. Com destaque para o fato de que a gramática envolve, além do nível estritamente estrutural, o nível semântico-pragmático, os marcadores discursivos são considerados como parte da gramática, já que exercem funções gramaticais. O foco da investigação se põe na atuação de bem e de bom como marcadores conversacionais, mas todas as funções encontradas são descritas e discutidas, propiciando-se, com essa indicação do universo de inserção, uma visão mais acurada do fato particular. No geral os resultados apontam diferenças funcionais no uso de cada um 


\section{REVISTA DA ABRALIN}

desses itens (em suas diversas funções), mas merece destaque o fato de que, quando funcionam como marcadores discursivos, os dois itens compartilham, dentro de sua classe, uma propriedade geral (textual/interpessoal): como registra a autora, a de "sinalizar um duplo movimento (de estruturação discursiva e de negociação), com presença significativa encabeçando respostas imediatas". De todo modo, conclui o estudo, o resultado da análise das peças depende do tipo de situação comunicativa daquele gênero discursivo em que funcionam.

$\mathrm{O}$ artigo seguinte, Extra-clausal constituents in Functional Discourse Grammar: function and form, de Riccardo Giomi e Evelien Keizer, desenvolve o que chama de "um primeiro esboço de uma abordagem abrangente aos constituintes extra-oracionais (CEOs) no quadro da Gramática Discursivo-Funcional (GDF)". A orientação se define contrariamente a estudos sobre gramaticalização e pragmaticalização que consideram esses elementos, tão diretamente ligados a funções do discurso, como "externos" à gramática em si, e também a estudos que retiram esses elementos de uma "gramática da sentença" (de relações intraoracionais) para pô-los em uma "gramática tética" (de relações extraoracionais). Inserindo-se registradamente no aparato teórico da "Functional Discourse Grammar (FDG)", o artigo defende que o que determina quais sejam as expressões que pertencem ao componente gramatical não é esse estatuto de 'interioridade', ou não, das expressões, em relação à oração, mas é o estatuto de 'interioridade', ou não, do seu "conteúdo semântico e pragmático" na estrutura da língua, ou seja, é o fato de existir, para elas, como dizem os autores, "uma codificação explícita e sistêmica na estrutura da língua"; assim, na proposta teórica da GDF, tudo o que um falante expressa morfossintaticamente e fonologicamente, cumprindo uma intenção comunicativa, tem estatuto gramatical. Registrando que a GDF ainda não tem uma determinação exata de qual seja a definição de um elemento como ECC ("extra-clausal constituent"), o estudo se propõe uma investigação das propriedades funcionais e formais dos elementos dessa classe (tão heterogeneamente instituída), estabelecendo, como pontos centrais de observação e de definição, a estrutura pragmática subjacente comum das peças (com sua contribuição para o desenvolvimento do discurso) e os fatores comunicativos que determinariam tão significativa ocorrência dessas peças na linguagem. Fica proposto, especificamente, que "cada CEO forma uma unidade de comportamento comunicativo separada, embora invariavelmente dependente, isto é um Ato Discursivo Subsidiário" (não componente da expressão que o precede, segue ou interrompe) chegando-se, por aí, a uma consideração do mecanismo que governa o posicionamento dos CEOs, em relação às unidades comunicativas a que eles se agregam, diferentemente do que apresenta a proposta vigente na GDF. Os autores consideram que o estudo obtém, de um lado, definir restrições funcionais sobre o posicionamento dos CEOs, e, de outro lado, estabelecer o maior grau de liberdade posicional de que gozam esses constituintes, relativamente aos que pertencem a camadas mais baixas da organização morfossintática.

No artigo seguinte, os autores Marta Anaisa Bezerra Ramos e Camilo Rosa põem sob exame uma questão particularmente interessante para uma análise funcional, que é a natureza das orações adverbiais de valor modal no português. O título, Orações adverbiais de modo introduzidas por sem/sem que: um olhar na tradição gramatical e outro nos usos, já condensa a indicação do objeto em exame, e a exposição, no seu todo, compõe um encaminhamento sempre direto para o tema em análise, o 


\section{REVISTA DA ABRALIN}

que dá grande unidade ao texto. Trata-se de uma questão que exibe singularidades, tanto no que concerne ao estatuto categorial dos conectores quanto no que concerne ao espectro semântico das construções adverbiais resultantes, valendo observar que essas orações não encontram classificação na Nomenclatura gramatical brasileira, e raramente têm abrigo nas obras gramaticais em geral. A artigo define uma base teórica funcionalista que concebe a gramática segundo pressupostos que assumem sua relação com o discurso bem como com a cognição. Para as análises, são adotados critérios de reconhecimento das relações modais estabelecidas com sem e sem que, distinguindo-as das demais relações adv, o que é bastante desafiador, considerando a grande flutuação de significado envolvida. O exame das orações iniciadas por sem e sem que que vem apresentado toma essas estruturas oracionais em um córpus formado por artigos de opinião, editoriais e entrevistas de periódicos semanais brasileiros. A análise revelou grande frequência de um valor modal para essas estruturas, propiciando o atingimento do objetivo já colocado como central, na proposição inicial do estudo, de demonstrar que existe um domínio particular de valor modal, não um domínio amplo que integra diluidamente esse valor, entre relações semânticas adverbiais diversas, como as de comparação, conformidade ou concessão.

O último artigo deste dossiê, Reaction to social quotas: a study of Facebook comments in Brazilian Portuguese, com autoria de Rodrigo Esteves de Lima Lopes, constitui um trabalho relevante não apenas para os estudos funcionalistas, em específico para a Gramática sistêmico-funcional, mas também para os estudos em Linguística de Corpus. O resumo informa, em uma formulação inicial bastante pragmática, que o objetivo do trabalho é "discutir como os usuários do Facebook reagiram às notícias de que a Universidade Federal da Bahia (Brasil) introduziu cotas sociais para transexuais, imigrantes e refugiados socialmente vulneráveis". E o texto já abre o todo da proposta com a informação de uma ancoragem em corpus, para descrição gramatical, e com o registro de uma direção lexicogramatical, para a análise. O abrigo no aparato sistêmico-funcional é especificado na indicação de que o foco principal do estudo é estabelecer os padrões de "transitividade" e de "avaliação" que os atores sociais representam. Para a coleta e o processamento dos dados, que são cuidadosamente especificados, apresenta-se uma condução que se ampara em análise estatística computacional. Quanto aos resultados, verificou-se, no geral, que a maior parte dos comentários em exame parte dos próprios usuários do Facebook em interação, e que esses comentários, nem sempre amigáveis, ocorrem nas interlocuções que acompanham as tomadas de posição dos falantes. Duas indicações particularmente relevantes são que, de um lado, as discussões são politicamente polarizadas, indo, no geral, para além de uma simples expressão de opiniões favoráveis ou contrárias ao sistema de cotas, e que, de outro lado, são comuns manifestações reveladoras de preconceito contra nordestinos e contra os próprios estados do Nordeste. É importante, no estudo, que, com apoio na teoria explicitada, podese identificar padrões gramaticais para cada um dos temas presentes nos comentários, e, finalmente, que, com apoio no direcionamento sistêmico-funcional de análise, puderam ser estabelecidos, a partir dos significados depreendidos nos comentários analisados, os sistemas de escolha relativos a avaliação e a transitividade. 


\section{REVISTA DA ABRALIN}

\section{O rescaldo da proposta}

Em uma visão geral, os artigos que compõem este dossiê organizam-se em dois grupos, quanto à natureza da proposta. Os três primeiros são dirigidos pela problematização de um ponto teórico: a legitimidade do contexto como uma categoria teórica na linguística sistêmico-funcional, no caso do texto de Pagano, e a pertinência de pressões comunicativas como categorias explicativas na tipologia linguística, nos casos de Levshina e Leufkens. O quarto artigo, de Mithun, problematiza uma prática tradicional nos estudos linguísticos e, particularmente, nos estudos tipológicos, a de ver as categorias gramaticais como inerentemente categóricas, isto é, como discretas. Assim, desenvolvendo essa questão teoricamente, Mithun propõe uma visão matizada das categorias gramaticais, por meio de uma análise dos estágios de gramaticalização das orações relativas na língua mohawk.

O artigo de Mithun entra como uma transição entre os três primeiros artigos, marcados pela discussão de princípios teóricos, e os quatro últimos, cuja proposta se direciona pela análise de fatos gramaticais específicos, em línguas particulares: a gramaticalização de marcadores discursivos no português (Gorski), as propriedades formais e funcionais de constituintes extraoracionais em inglês (Giomi; Keizer), a distribuição discursiva de orações adverbiais modais em português (Ramos; Rosa) e as escolhas lexigramaticais na constituição dos discursos sobre cotas sociais em português (Lima-Lopes).

No conjunto, o dossiê reúne estudos que abrem o campo de visão do leitor, descobrindo bases e diretrizes de relevantes teorias de orientação funcionalista, ao lado de estudos que fixam a atenção do leitor em análises orientadas ou matizadas com sustentação funcional.

Ao final, nós, os organizadores desta obra, gostaríamos de agradecer todos os autores e pareceristas pela excelente contribuição para o dossiê e por tão prontamente aceitarem os prazos apertados que tiveram de ser impostos. 